\title{
Is muscle the major site of insulin resistance in Type 2 (non-insulin-dependent) diabetes mellitus?
}

\author{
J.E.Gerich \\ Clinical Research Center, Departments of Medicine and Physiology, University of Pittsburgh School of Medicine, Pittsburgh, USA
}

Liver and muscle are the two major insulin-sensitive tissues responsible for maintenance of normal glucose homeostasis. In Type 2 (non-insulin-dependent) diabetes mellitus, both these tissues are resistant to insulin [1-5]. At the present time, muscle is widely regarded as the more important site $[2,5-8]$. The main reasons for this view are the impressions that muscle is more insulin-resistant than liver, that muscle is more important than liver for glucose homeostasis, and that increased hepatic glucose output is a late event in Type 2 diabetes. In this article, I shall briefly examine some of the experimental evidence for these impressions and present arguments which question their validity.

\section{Is muscle less sensitive to insulin than liver in Type 2 diabetes?}

Strictly speaking, to answer this question, one must perform dose-response experiments and demonstrate that the $\mathrm{ED}_{50}$ for the action of insulin on muscle is increased to a greater extent than the $E D_{50}$ for the action of insulin on liver. A great many glucose clamp experiments have been performed in subjects with Type 2 diabetes comparing suppression of glucose production (GP) and stimulation of glucose utilization (GU) as indices of insulin action on liver and muscle. Unfortunately, almost all these studies used only one insulin infusion rate and the plasma insulin concentration achieved ( $(100 \mathrm{mU} / \mathrm{l})$ produced maximal or near-maximal suppression of GP. Thus, the results of such studies cannot be used to compare hepatic and muscle insulin sensitivity. Moreover, because of marked differences in the dose-response kinetics for the effect of insulin on GP and GU, use of such high insulin concentrations can lead to overestimation of the resistance of GU compared to GP; for example, GP can be suppressed by only $2 \mathrm{mg} \cdot \mathrm{kg}^{-1} \cdot \mathrm{min}^{-1}$, whereas GU can be increased by as much as $5-10 \mathrm{mg} \cdot \mathrm{kg}^{-1} \cdot \mathrm{min}^{-1}$ depending on the insulin concentration used.

Three studies to date $[1,3,4]$ have attempted dose-response experiments. In one study [1], non-diabetic and diabetic subjects were not adequately matched for age and gender. Furthermore, it was not possible, because of the insulin doses used, to obtain reliable estimates of the $\mathrm{ED}_{50}$ for suppression of hepatic glucose output. The investigators did not conclude that muscle was the more insulin-resistant tissue. In the second study [3], subjects were well matched and the insulin doses used permitted estimation of the kinetic parameters of insulin action on both tissues; the $\mathrm{ED}_{50}$ s for suppression of GP and stimulation of GU were found to be comparably increased in diabetic subjects. In the third study [4], the $\mathrm{ED}_{50}$ for suppression of GP was increased two-fold in the diabetic subjects but, because of the limited insulin concentrations used, no kinetic parameters could be calculated for GU; however, the investigators did conclude that at physiologic insulin concentrations impaired suppression of GP contributes quantitatively more than defective $\mathrm{GU}$.

Thus, the only study that has adequately compared hepatic and muscle insulin sensitivity in Type 2 diabetes found them to be equally impaired. Further studies are needed to substantiate these findings before they can be accepted as fact. Nevertheless, one can conclude that at present there are no data which demonstrate that muscle is less sensitive to insulin than liver. Furthermore, although clamp experiments have proven useful in quantifying the effect of insulin on GP and GU, it is worth emphasizing that the results of such experiments may not predict the alterations in GP and GU that occur under clinical conditions (e.g., meal ingestion, see below) in which plasma insulin and glucose concentrations are free to change and influence one another.

\section{Does decreased muscle glucose uptake precede increased hepatic glucose output?}

The finding that hyperinsulinaemic mildly hyperglycaemic individuals with Type 2 diabetes have "normal" GP and reduced systemic glucose clearance (GC) has been put forward as evidence that peripheral tissue (presumably muscle) insulin resistance is a more important early defect in Type 2 diabetes [7]. However, recent studies from our laboratory (Fig. 1 and Table 1) indicate that in four groups of age, weight and gender-matched in- 


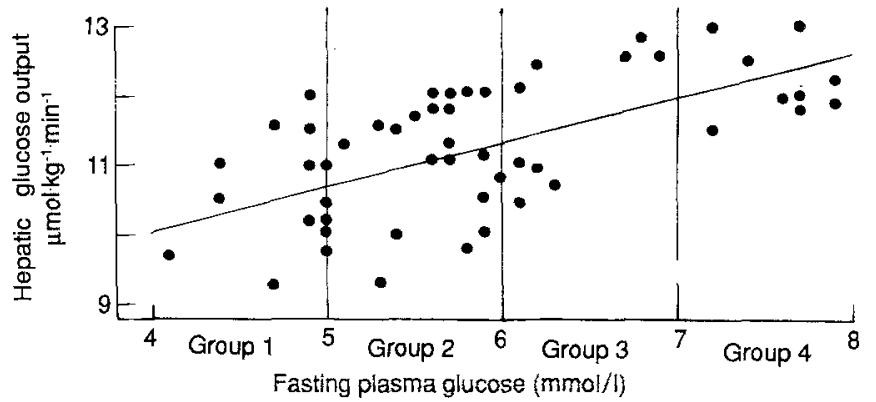

Fig. 1. Hepatic glucose output in age, weight and gender-matched subjécts with fasting plasma glucose concentration between 4 and $8 \mathrm{mmol} / \mathrm{l}$. (See also Table 1 )

$r=0.59, p=0.001$

dividuals, rates of hepatic GP are linearly correlated with fasting plasma glucose concentrations even within the normal range. Furthermore, individuals with fasting plasma glucose concentrations between 6 and $7 \mathrm{mmol} / \mathrm{l}$, whose muscle GU is normal or increased [9], have rates of GP that are significantly greater than those in individuals with plasma glucose concentrations between 4 and $5 \mathrm{mmol} / \mathrm{l}$.

The reduction in systemic GC found in mildly hyperglycaemic subjects can be largely explained by reduced brain GC since brain glucose uptake does not increase appreciably as plasma glucose concentrations increase [9]. Because of this, systemic GC decreases even in nondiabetic subjects who are made hyperglycaemic [10]. Finally although muscle GC may be reduced in Type 2 diabetes [9], this may not be entirely due to insulin resistance, since hyperglycaemia reduces muscle GC in nondiabetic subjects [11].

$\mathrm{GC}$, an index of the suitability of $\mathrm{GU}$ for the prevailing plasma glucose concentration, is calculated by dividing $\mathrm{GU}$ by the plasma glucose concentration. It is fallacious to compare $\mathrm{GC}$, a derived rate, with an absolute rate for GP. There is no comparable expression to evaluate the suitability of GP, but a GP that is not reduced in a hyperglycaemic-hyperinsulinaemic individual must be inappropriate.

Additionally, it is important to point out that plasma glucose concentrations change because of absolute differences in rates of GP and GU - not because of differences in their suitability. For plasma glucose to increase, GP must exceed GU. This can occur because GU decreases, GP increases or a combination of these changes. No report $[2,9,12-14]$ simultaneously examining GP and muscle GU in overnight-fasted subjects with Type 2 diabetes has found reduced muscle GU, whereas virtually all have found increased GP.

One may thus conclude that at the present time, there is no compelling evidence that decreased muscle glucose uptake precedes increased hepatic glucose output in Type 2 diabetes; indeed the data suggest the opposite.

\section{Is muscle the more important tissue for glucose homeostasis?}

It is possible that, although liver and muscle may be equally insulin resistant in Type 2 diabetes, a comparable degree of muscle insulin resistance may produce more profound abnormalities because of the relative importance of muscle for glucose homeostasis. To examine this issue, I shall consider the postabsorptive (fasting) and postprandial states separately.

In the postabsorptive state, most GU occurs independent of insulin and only about $25 \%$ of GU $\left(\sim 2.5 \mu \mathrm{mol} \cdot \mathrm{kg}^{-1} \cdot \mathrm{min}^{-1}\right)$ is accounted for by muscle $[13,15-18]$. In contrast, $100 \%$ of GP $\left(\sim 10 \mu \mathrm{mol} \cdot \mathrm{kg}^{-1}\right.$. $\mathrm{min}^{-1}$ ) is due to the liver and is very sensitive to insulin [3]. Thus, a relatively minor ( $25 \%$ ) fluctuation in GP would exert an influence about four-fold greater on plasma glucose concentration than a comparable fluctuation in muscle GU.

Additional evidence favouring the importance of the liver in the postabsorptive state is the fact that plasma insulin concentrations found in the postabsorptive state have a more profound effect on GP than GU: a doubling of the basal plasma insulin concentration suppresses GP by about $30-50 \%[4,19,20]$ while having no effect on $\mathrm{GU}$ $[4,19]$.

Finally, as mentioned earlier, in hyperglycaemic-hyperinsulinaemic Type 2 diabetic subjects, hepatic GP is increased above normal and correlated with the fasting hyperglycaemia while muscle $\mathrm{GU}$ is either normal or increased [2, 9, 12-14]. Thus, hyperglycaemia and hyperinsulinaemia are able to compensate for muscle insulin resistance but not hepatic insulin resistance. It is, therefore, most likely that hepatic rather than muscle insulin resistance is the dominant factor responsible for the initiation and maintenance of fasting hyperglycaemia in Type 2 diabetic subjects.

In the postprandial state, the major determinants of plasma glucose fluctuations are the suppression of endogenous GP and uptake of glucose by splanchnic tissues, muscle and brain $[13,14,18,21,22]$. After ingestion of a meal or glucose load, endogenous GP is reduced by approximately $60 \%$. A widely quoted study [23] has concluded that the great majority of an oral glucose load is taken up by muscle. In that study, 65 g glucose was calculated to be taken up by muscle of subjects whose splanchnic glucose output was only $61 \mathrm{~g}$. Mathematically it is impossible for muscle $G U$ to exceed the systemic delivery of glucose (in the absence of hypoglycaemia). Moreover, these calculations would leave no glucose to be taken up by brain, a physiologic impossibility. Thus, the validity of these observations is open to serious question. Other studies $[13,14,18,21,22]$ indicate that muscle takes up about $30 \%$ of an oral glucose load and that brain and splanchnic tissues, respectively, take up $20-25 \%$ and $30-$ $35 \%$ of the load.

Relating the results of these studies to overall glucose homeostasis after ingestion of a $70 \mathrm{~g}$ oral glucose load by a $75 \mathrm{~kg}$ normal subject (Table 2) indicates that muscle would take up $30 \mathrm{~g}$ glucose and splanchnic tissues would take up about $35 \mathrm{~g}$ glucose. In addition, however, the liver would reduce its output of glucose by about $25 \mathrm{~g}$. Thus, changes in splanchnic GU and GP (a total of $60 \mathrm{~g}$ ) would appear to be more important than changes in muscle GU $(-30 \mathrm{~g})$ for normal postprandial glucose homeostasis. Consequently, one would expect that hepatic insulin resistance would have a more profound effect on postprandial 
Table 1. Hepatic glucose output in age, weight and gender-matched subjects with fasting plasma glucose concentration between 4 and $8 \mathrm{mmol} / \mathrm{l}$

\begin{tabular}{|c|c|c|c|c|}
\hline & Group 1 & Group 2 & Group 3 & Group 4 \\
\hline$\overline{\text { Hep }}$ & $10.6 \pm 0.2$ & $11.2 \pm 0.2$ & $11.7 \pm 0.3^{\mathrm{a}}$ & $12.1 \pm 0.2^{\mathrm{a}}$ \\
\hline Insul & $8.9 \pm$ & $10.5 \pm 0.6$ & $13.1 \pm 1.1^{\mathrm{a}}$ & $10.8 \pm 0.7$ \\
\hline Body mass index $\left(\mathrm{kg} / \mathrm{m}^{2}\right)$ & $25.6 \pm 0.9$ & $25.8 \pm 0.8$ & $25.8 \pm 0.8$ & $26 \pm 1.1$ \\
\hline Age (years) & $54 \pm 3$ & $49 \pm 2$ & $54 \pm 2$ & $51 \pm 3$ \\
\hline
\end{tabular}

a $p<0.01$ vs Group 1 ( See also Figure 1)

Table 2. Summary of postabsorptive and postprandial glucose homeostasis

\begin{tabular}{lcc}
\hline & $\begin{array}{c}\text { Normal } \\
\text { subjects }\end{array}$ & $\begin{array}{c}\text { Type } 2 \\
\text { diabetic } \\
\text { patients }\end{array}$ \\
\hline Postabsorptive & & \\
Hepatic glucose output $/ 5 \mathrm{~h}$ & $45 \mathrm{~g}$ & $60 \mathrm{~g}$ \\
Muscle glucose uptake $5 \mathrm{~h}$ & $11 \mathrm{~g}$ & $14 \mathrm{~g}$ \\
Glycosuria/5 h & 0 & $10 \mathrm{~g}$ \\
Tissue glucose uptake/5 h & $45 \mathrm{~g}$ & $50 \mathrm{~g}$ \\
Postprandial & & \\
Suppression of endogenous glucose & $25 \mathrm{~g}$ & $15 \mathrm{~g}$ \\
appearance & & \\
Residual endogenous glucose appearance & $20 \mathrm{~g}$ & $45 \mathrm{~g}$ \\
Systemic appearance of oral glucose & $55 \mathrm{~g}$ & $55 \mathrm{~g}$ \\
Overall systemic glucose appearance & $75 \mathrm{~g}$ & $100 \mathrm{~g}$ \\
First-pass splanchnic glucose uptake & $15 \mathrm{~g}$ & $15 \mathrm{~g}$ \\
Splanchnic uptake of systemic glucose & $20 \mathrm{~g}$ & $22 \mathrm{~g}$ \\
Total splanchnic glucose uptake & $35 \mathrm{~g}$ & $37 \mathrm{~g}$ \\
Muscle glucose uptake & $30 \mathrm{~g}$ & $33 \mathrm{~g}$ \\
Brain glucose uptake & $20 \mathrm{~g}$ & $20 \mathrm{~g}$ \\
Adipose and other tissue glucose uptake & $5 \mathrm{~g}$ & $10 \mathrm{~g}$ \\
Glycosuria & 0 & $15 \mathrm{~g}$ \\
Total tissue glucose uptake & $75 \mathrm{~g}$ & $85 \mathrm{~g}$ \\
\hline
\end{tabular}

a Over $5 \mathrm{~h}$ after ingestion of $70 \mathrm{~g}$ glucose load in a $75 \mathrm{~kg}$ subject calculations based on data from Kelley et al. [18], Mitrakou et al. [14], Katz et al. [23], Firth et al. [13], Ferrannini et al. [21], Jackson et al. [22], and Marin et al. [29]

glucose homeostasis than a comparable degree of muscle insulin resistance.

This conclusion is supported by studies examining muscle $\mathrm{GU}$ and hepatic GP after glucose or meal ingestion in Type 2 diabetes [13, 14, 24-27]. No study has found reduced muscle GU [13, 14, 24-26], whereas all have found reduced suppression of GP $[13,14,24,25,27]$. Since there is no compensatory increase in first-pass splanchnic glucose uptake $[13,14]$, this reduced suppression of hepatic GP increases systemic delivery of glucose $[13,14,24-26$, 28]. It stands to reason, therefore, that postprandial hyperglycaemia in Type 2 diabetes should be attributed primarily to increased delivery of glucose to the systemic circulation.

As summarized in Table 2, Type 2 diabetes is usually characterized by increased tissue glucose uptake. Reduced effectiveness of glucose uptake by muscle and other tissues may exacerbate postprandial hyperglycaemia, but reduced GU cannot be the primary defect since tissue GU in absolute terms is not reduced, whereas GP in absolute terms is increased. Thus, as in the postabsorptive state, hyperglycaemia and hyperinsulinaemia in the postprandial state appear to be able to compensate for muscle insulin resistance but not for hepatic insulin resistance.

\section{Summary and conclusions}

Examination of experimental data, as well as physiologic considerations, fail to provide compelling support for the prevalent belief that muscle is the most important site of insulin resistance in Type 2 diabetes, rather they support the view that abnormal hepatic glucose production is the major factor responsible for both fasting and postprandial hyperglycaemia.

At the present time considerable resources are being applied to develop agents which improve GU in Type 2 diabetes; but $\mathrm{GU}$ is normal or increased in this condition $[3,5,7,13,14,24,25]$. It would seem preferable in the future that more effort be directed toward determining the mechanism(s) responsible for the abnormal hepatic glucose production and developing specific therapeutic agents to treat it. The mechanisms responsible for abnormal hepatic glucose production in Type 2 diabetes remain unclear, but factors such as hyperglucagonaemia, increased hepatic fat oxidation, increased availability of gluconeogenic substrates, impaired generation/effectiveness of intracellular insulin signals, and impaired insulin secretion all deserve consideration.

Acknowledgements. Work cited from the author's laboratory has been supported by grants from the USPHS (DK20411 and RR00056), the American Diabetes Association, and the Juvenile Diabetes Foundation, International. The excellent editorial assistance of Ms. C. Butler is gratefully acknowledged.

\section{References}

1. Kolterman O, Gary R, Griffin J, Burstein P, Insel J, Scarlett J, Olefsky J (1981) Receptor and postreceptor defects contribute to the insulin resistance in noninsulin-dependent diabetes mellitus. J Clin Invest 68: 957-969

2. DeFronzo R, Gunnarsson R, Bjorkman O, Olsson M, Wahren J (1985) Effects of insulin on peripheral and splanchnic glucose metabolism in noninsulin-dependent (Type 2) diabetes mellitus. J Clin Invest 76: 149-155

3. Campbell P, Mandarino L, Gerich J (1988) Quantification of the relative impairment in actions of insulin on hepatic glucose production and peripheral glucose uptake in noninsulin-dependent diabetes mellitus. Metabolism 37:15-22

4. Groop LC, Bonadonna RC, DelPrato S, Ratheiser K, Zyck K, Ferrannini E, DeFronzo RA (1989) Glucose and free fatty acid metabolism in noninsulin-dependent diabetes mellitus. Evidence for multiple sites of insulin resistance. J Clin Invest 84: 205-213

5. Bogardus C, Lillioja S, Howard B, Reaven G, Mott D (1984) Relationship between insulin secretion, insulin action, and fasting plasma glucose concentration in nondiabetic and noninsulin-dependent diabetic subjects. J Clin Invest 74: 1238-1246

6. Chen YD, Jeng CY, Hollenbeck C, Wu MS, Reaven G (1988) Relationship between plasma glucose and insulin concentration glucose production and glucose disposal in normal subjects and patients with noninsulin-dependent diabetes. J Clin Invest 82: $21-25$

7. DeFronzo R, Ferrannini E, Simonson D (1989) Fasting hyperglycaemia in noninsulin-dependent diabetes mellitus: contributions of excessive hepatic glucose production and impaired tissue glucose uptake. Metabolism 38: 387-395

8. Beck-Nielsen $H$ (1989) Insulin resistance in skeletal muscles of patients with diabetes mellitus. Diab Metab Rev 5: 487-493

9. Gerich J, Mitrakou A, Kelley D, Mandarino L, Nurjhan N, Reilly J, Jenssen T, Veneman T, Consoli A (1990) Contribution of im- 
paired muscle glucose clearance to reduced postabsorptive systemic glucose clearance in NIDDM. Diabetes 39: 211-216

10. Gottesman I, Mandarino L, Gerich J (1984) Use of glucose uptake and glucose clearance for the evaluation of insulin action in vivo. Diabetes 33: 184-191

11. Yki-Jarvinen H, Young AA, Lamin C, Foley JE (1987) Kinetics of glucose disposal in whole body and across of forearm in man. J Clin Invest 79: 1713-1719

12. Capalbo B, Santoro D, Riccardi G, Perrotti N, Sacca L (1986) Direct evidence for a stimulatory effect of hyperglycaemia per se on peripheral glucose disposal in Type 2 diabetes. J Clin Invest 77: 1285-1290

13. Firth R, Bell P, Marsh H, Hansen I, Rizza R (1986) Postprandial hyperglycaemia in patients with noninsulin-dependent diabetes mellitus: roles of hepatic and extrahepatic tissues. J Clin Invest 77: $1525 \cdots 1532$

14. Mitrakou A, Kelley D, Veneman T, Jenssen T, Pangburn T, Reilly J, Gerich J (1990) Contribution of abnormal muscle and liver glucose metabolism to postprandial hyperglycaemia in noninsulindependent diabetes mellitus. Diabetes 39: 1381-1390

15. Andres R, Cader G, Zierler K (1956) The quantitatively minor role of carbohydrate in oxidative metabolism by skeletal muscle in intact man in the basal state. Measurements of oxygen and glucose uptake and carbon dioxide and lactate production in the forearm. J Clin Invest 35: 671-682

16. DeFronzo R, Jacot E, Jequier E, MaederE, Wahren J, Felber J-P (1981) The effect of insulin on the disposal of intravenous glucose. Results from indirect calorimetry and hepatic and femoral venous catheterization. Diabetes 30: 1000-1007

17. Baron A, Brechtel G, Wallace P, Edelman S (1988) Rates and tissue sites of noninsulin-dependent and insulin-mediated glucose uptake in humans. Am J Physiol 255: E769-744

18. Kelley D, Mitrakou A, Marsh H, Schwenk F, Benn J, Sonnenberg $\mathrm{G}$, Archangeli M, Aoki T, Sorensen J, Berger M, Sonksen P, Gerich J (1988) Skeletal muscle glycolysis, oxidation, and storage of an oral glucose load. J Clin Invest 81: 1563-1571

19. Bonadonna R, Groop L, Kraemer N, Ferrannini E, DelPrato S, DeFronzo $R$ (1990) Obesity and insulin resistance in humans: a dose-response study. Metabolism 39: 452-459

20. Nurjhan N, Kennedy F, Consoli A, Martin C, Miles J, Gerich J (1988) Quantification of the glycolytic origin of plasma glycerol as an index of lipolysis in vivo. Metabolism 37: 371-377
21. Ferrannini E, Bjorkman O, Reichard G, Pilo A, Olsson M, Wahren J, DeFronzo R (1985) The disposal of an oral glucose load in healthy subjects: a quantitative study. Diabetes 34: 580588

22. Jackson R, Roshania R, Hawa M, Sim B, DiSilvio L (1986) Impact of glucose ingestion on hepatic and peripheral glucose metabolism in man: an analysis based on simultaneous use of the forearm and double isotope techniques. J Clin Endocrinol Metab 63: $541-549$

23. Katz L, Glickman M, Rapoport S, Ferrannini E, DeFronzo R (1983) Splanchnic and peripheral disposal of oral glucose in man. Diabetes 32: 675-679

24. McMahon M, Marsh H, Rizza R (1989) Effects of basal insulin supplementation on disposition of a mixed meal in obese patients with NIDDM. Diabetes 38: 291-303

25. Firth R, Bell P, Marsh M, Rizza R (1987) Effect of tolazamide and exogenous insulin on pattern of postprandial carbohydrate metabolism in patients with noninsulin-dependent diabetes mellitus. Diabetes 36: 1130-1138

26. Jackson R, Perry G, Rogers J, Advani U, Pilkington T (1973) Relationship between the basal glucose concentration, glucose tolerance, and forearm glucose uptake in maturity-onset diabetes. Diabetes 22: 751-761

27. Ferrannini E, Simonson D, Katz L, Reichard G, Bevilacqua S, Barrett E, Olsson M, DeFronzo R (1988) The disposal of an oral glucose load in patients with noninsulin-dependent diabetes. Metab 37: 79-85

28. Osei K (1987) The role of splanchnic glucose output in determining glycemic responses after mixed meal in Type 2 diabetic patients and normal subjects. Pancreas 2: 386-392

29. Marin P, Rebuffe-Scrine M, Smith U, Bjorntorp P (1987) Glucose uptake in human adipose tissue. Metabolism 36: 1154-1160

Dr. J.E. Gerich

University of Pittsburgh

Clinical Research Center

3488 Presbyterian-University Hospital

230 Lothrop Street

Pittsburgh, PA 15261

USA 